\title{
Geographic Analysis of Burn Severity for the 2013 California Rim Fire
}

\author{
Christopher Potter \\ NASA Ames Research Center, Moffett Field, CA, USA \\ Email: chris.potter@nasa.gov
}

Received 26 May 2014; revised 28 June 2014; accepted 9 July 2014

Copyright (C 2014 by author and Scientific Research Publishing Inc.

This work is licensed under the Creative Commons Attribution International License (CC BY). http://creativecommons.org/licenses/by/4.0/

(c) $\underset{\mathrm{EY}}{\mathrm{i}}$ Open Access

\begin{abstract}
Analysis of Landsat imagery was applied to classify burn severity within the 2013 Rim Fire area using the relative difference normalized burn ratio (RdNBR). Results showed 53,220 ha in the High Burn Severity (HBS) class and another 34,214 ha in the Moderate Burn Severity (MBS) class. Within Yosemite National Park, 12,084 ha were detected by RdNBR analysis in the HBS class and another 11,089 ha in the MBS class. The most typical ecosystem habitat detected within the HBS class was Ponderosa pine-Mixed Conifer forest, between the elevations of 1000 and 2000 meters or on slopes between 5 and 30 percent. Most of the HBS areas were located in areas where high levels of pre-fire fuels were quantified by 2013 Landsat vegetation index (NDVI) values between 500 and 800. The Low Burn Severity (LBS) class covered a higher fraction of areas where the duration since last fire (YSF) was less than 25 years, compared to the HBS class, which covered a higher fraction of areas where the YSF was greater than 60 years.
\end{abstract}

\section{Keywords}

Wildfire, California, Burn Severity, Landsat, Remote Sensing

\section{Introduction}

The Rim Fire started east of Groveland (Tuolumne County) on August 17, 2013 in the Stanislaus National Forest of the central Sierra Nevada of California. The fire burned over an estimated 104,131 ha (257,314 acres) before it was largely contained around September 17, 2013 [1]. This made the Rim Fire the largest wildfire on record for the Sierra Nevada. Approximately 31,263 ha (77,254 acres) were reportedly burned within Yosemite National Park [2].

During the summer of 2013, fuel moisture was critically low in the central Sierra Nevada due to prolonged drought [1]. The probability of ignition and rapid fuel consumption was very high in the months leading up to 
the Rim Fire. In the Stanislaus National Forest, there were ground observations of the Rim Fire completely burning dense stands of pine trees and other woody vegetation. In the higher elevations within Yosemite National Park (YNP), and notably around Hetch Hetchy Reservoir, the Rim Fire generally burned as a low(er) intensity, slower-moving ground fire below tree crowns, due to the thinner forest stands and exposed granitic outcrops [3]. The National Park Service (NPS) policy of allowing recent fires to burn when they do not threaten property or lives may have played a role in the controlling fire intensity within YNP.

"Burn severity" is one of the most commonly mapped measures of wildfire effects on vegetation and soils [4]. The Normalized Burn Ratio (NBR) computed from Landsat infrared bands is primarily sensitive to live chlorophyll and water content of vegetation and soils, but it is also responsive to canopy lignin, hydrous minerals, ash and char [5]. The NBR is also called the normalized difference water index (NDWI) and has been validated in the field repeatedly as an index of fire fuel moisture [6]-[9]. Similarly, the mid-summer normalized difference vegetation index (NDVI) from Landsat has been shown to be proportional to conifer and deciduous hardwood forest components of heavy fuel loads in YNP [10].

Most burn severity mapping applications have subtracted a post-fire NBR image from a pre-fire NBR image to derive the "differenced NBR" (dNBR) product [11]. In this study, the dNBR product for the 2013 Rim Fire area was categorized into burn severity classes and analyzed by numerous landscape variables, including pre-fire NDVI, to aid in understanding the geographic variation in the effects of this historic fire event.

\section{Methods}

Cloud-free imagery from the Landsat 8 Enhanced Thematic Mapper (ETM) sensor was selected from the US Geological Survey Earth Explorer data portal (http://earthexplorer.usgs.gov/). Pre-fire Landsat 8 image data from path/row 43/34 were acquired for 30 July 2013, near the peak of the summer season in Sierra Nevada. For burn severity mapping, post-fire Landsat 8 imagery from 18 October 2013 was acquired.

All images used in this study were geometrically registered using terrain correction algorithms (Level 1T) applied by the US Geological Survey EROS Data Center, and then converted to at-sensor reflectance following the algorithms from [12]. No further corrections for atmospheric scattering were applied, since the reflectance indices used in this study employed near-infrared (NIR) and short wave infrared (SWIR) wavelengths that are minimally affected by atmospheric scattering [13], especially during the summer months for the Sierra Nevada study area [4].

Burn severity at 30-m ground resolution was determined using the normalized burn ratio (NBR, [11], derived from the NIR and SWIR bands (4 and 7, respectively) of the Landsat TM sensors.

$$
\mathrm{NBR}=(\mathrm{NIR}-\mathrm{SWIR}) /(\mathrm{NIR}+\mathrm{SWIR})
$$

NBR (scaled by 1000 to an integer format) is influenced by land surface conditions, such as canopy density and soil surface charring. The relative differenced NBR was computed as a comparison of pre- and post-fire surface conditions for the fire events listed in Table 1.

$$
\text { RdNBR }=[(\text { NBRpre }- \text { fire }- \text { NBR post }- \text { fire })] / \sqrt{\text { ABS (NBRpre }- \text { fire })}
$$

The absolute value (ABS) of the pre-fire NBR in the denominator allowed computation of the square-root without changing the sign of the dNBR [4]. Positive RdNBR values would represent a decrease in vegetation cover and a higher burn severity, while negative values would represent an increase in vegetation cover.

Following protocols from the composite burn index (CBI; [14], three burn severity classes were defined for conifer forest types of California by Miller et al. [4] by the RdNBR values: Unburned < 1, Low 1 - 250, Moderate $251-600$, and High > 600. Within the CBI protocol, the low severity class was generally associated with little change in vegetation cover, whereas the high severity class was generally associated with complete mortality of live vegetation, i.e. stand replacing fire.

The normalized difference vegetation index (NDVI) has been commonly used in disturbance ecology to monitor fire impacts and recovery trajectories [15]. NDVI exploits differential reflectance between the red and near-infrared (NIR) portions of the spectrum by the equation:

$$
\mathrm{NDVI}=(\mathrm{NIR}-\mathrm{Red}) /(\mathrm{NIR}+\mathrm{Red})
$$

where NIR is the reflectance of wavelengths from 0.76 to $0.9 \mu \mathrm{m}$ and Red is the reflectance from 0.63 to $0.69 \mu \mathrm{m}$. Pre-fire NDVI (for 30 July 2013) was scaled from 0 to 1000, increasing with higher live green canopy cover. 
Table 1. Pre-fire land cover (CDL 2012) fractional areas within Rim Fire burn severity classes.

\begin{tabular}{ccccc}
\hline Land Cover Class & \% LBS & \% MBS & \% HBS & \% All Burned Area \\
\hline Developed Open & 0.8 & 0.3 & 0.2 & 0.5 \\
Developed Low & 0.2 & 0.0 & 0.0 & 0.1 \\
Barren & 5.2 & 1.9 & 0.2 & 2.9 \\
Deciduous Forest & 1.1 & 0.3 & 0.1 & 0.6 \\
Evergreen Forest & 55.2 & 58.6 & 56.7 & 56.4 \\
Shrubland & 32.0 & 34.4 & 40.5 & 35.3 \\
Grassland & 3.9 & 3.8 & 2.1 & 3.3 \\
\hline
\end{tabular}

A 100-meter grid resolution map layer was generated to estimate the years since the last previous wildfire from the fire perimeter database compiled by the California Department of Forestry, Fire and Resource Assessment Program (FRAP; data available at http://frap.cdf.ca.gov/).

Summaries of landscape variables were generated as burn severity class statistics for all 30-m Landsat pixels. For plots, a sample of 2000 points randomly selected across the Rim Fire area was used. Tests of statistical significance between classes were carried out using the two-sample Kolmogorov-Smirnov (K-S) test, a non-parametric method that compares the cumulative distributions of two data sets [16]. The K-S test does not assume that data were sampled from Gaussian distributions (nor any other defined distributions), nor can its results be affected by changing data ranks or by numerical (e.g., logarithm) transformations. The K-S test reports the maximum difference between the two cumulative distributions, and calculates a $p$ value from that difference and the sample sizes. It tests the null hypothesis that both groups were sampled from populations with identical distributions according to different medians, variances, or outliers. If the K-S $p$ value is small (i.e., $<0.05)$, it can be concluded that the two groups were sampled from populations with significantly different distributions.

\section{Results}

\subsection{Area Burned}

Results from the Rim Fire RdNBR analysis detected 53,220 ha in the High Burn Severity (HBS) class and another 34,214 ha in the Moderate Burn Severity (MBS) class (Figure 1), which is a 1.6:1 ratio of HBS:MBS areas. This combined (HSB + MBS) area estimate was 84\% of (or 16,700 ha [41,266 acres] lower than) the CAL FIRE 2013 [1] incident estimate of the total burned area. If the 71,333 ha detected in the RdNBR Low Burn Severity (LBS) class were added, then the total area affected by the Rim Fire would have been 158,568 ha, or 52\% higher than the CAL FIRE 2013 [1] incident estimate.

Outside of YNP, the largest extents of HBS area detected by RdNBR analysis (from north to south) were centered around Bear Creek, Eleanor Creek, Jawbone Forest Service Station, Jones Meadow, Spinning Wheel Forest Service Station, and the Moccasin Lower Dam. Within YNP, 12,084 ha were detected by RdNBR analysis in the HBS class and another 11,089 ha in the MBS class, which is much closer to a 1:1 ratio of HBS:MBS than was estimated for the entire Rim Fire area. The largest extents of HBS area in YNP were detected in the vicinity of the historical Base Line Camp, Cottonwood Meadow, and to the southwest of both Bald Mountain and Smith Peak.

\subsection{Pre-Fire Land Cover}

Land cover classification for this study was based on the most recent US Forest Service CALVEG product [17] and the 2012 USDA National Agricultural Statistics Service (NASS) California Cropland Data Layer (CDL) (available at http://nassgeodata.gmu.edu/CropScape). The 30-meter resolution CDL is produced using satellite imagery from Landsat and the Indian Remote Sensing RESOURCESAT-1 (IRS-P6) Advanced Wide Field Sensor (AWiFS) collected during the summer growing season.

The predominant pre-fire land cover class in all burn severity classes was evergreen forest at an overall frac- 
tional coverage of 56\% (Table 1). The CALVEG layer shows the majority of these forests classified as Ponderosa pine-Mixed Conifer. Shrubland was the next most common pre-fire land cover type in the Rim Fire burned areas at an overall fractional coverage of 35\%. The CALVEG layer shows the majority of these shrubland areas classified as lower montane chaparral and canyon live oak. The fractional shrubland cover increased from $32 \%$ in LBS areas to $41 \%$ in HBS areas. The pre-fire fractional coverage of land classified as deciduous forest, grassland, and developed open cover were all two to ten times lower in HBS areas as in LBS areas.

\subsection{Pre-Fire Fuel by NDVI}

The majority of HBS areas were located in areas where the pre-fire NDVI was greater than 400, with many HBS areas clustered in areas where pre-fire NDVI was between 500 and 800 (Figure 2). Comparisons of the frequency distributions of pre-fire NDVI values showed a significant difference (K-S $p<0.001$ ) between the sampled LBS and HBS classes. When all Rim Fire burned areas were categorized, the HBS class areas showed the highest mean pre-fire NDVI, followed by MBS and LBS classes, with a 90 NDVI unit average difference between the LBS and HBS categories (Table 2).

\subsection{Elevation}

The majority of HBS areas were located between the elevations of 1000 and 2000 meters, with few HBS areas detected at elevations higher than 2500 meters (Figure 3). Comparisons of the frequency distributions of elevation values showed a significant difference (K-S $p<0.001$ ) between the sampled LBS and HBS classes. When

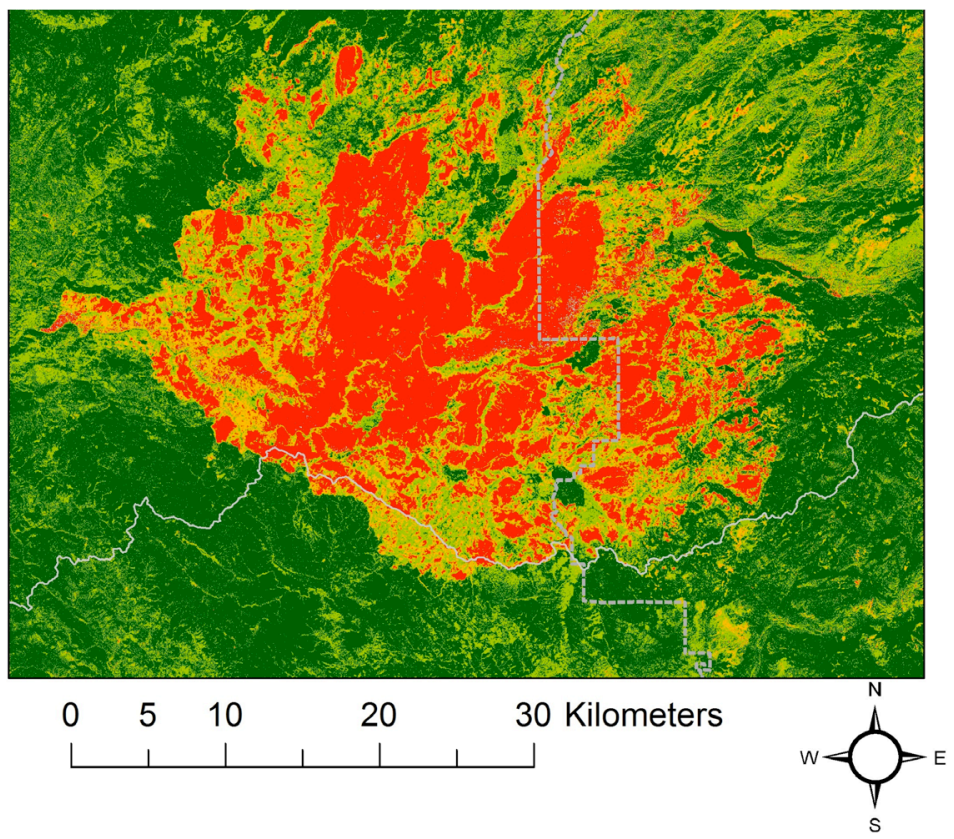

Burn Severity Classes

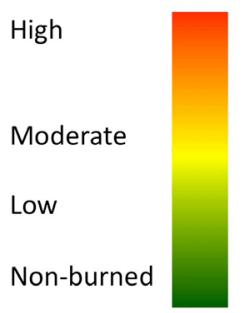

Figure 1. Results from RdNBR analysis of Landsat imagery (30-meter pixel resolution) for the 2013 Rim Fire area. County boundaries (solid) and the Yosemite National Park boundary (dashed) are shown in lighter lines. 


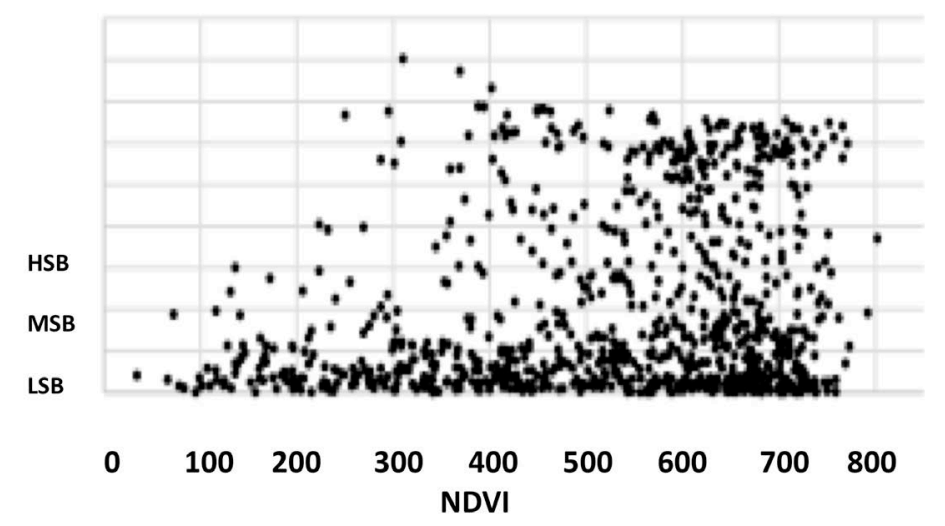

Figure 2. Plot of the sampled $(n=2000)$ frequency distributions of the Rim Fire RdNBR values by 2013 pre-fire Landsat NDVI.

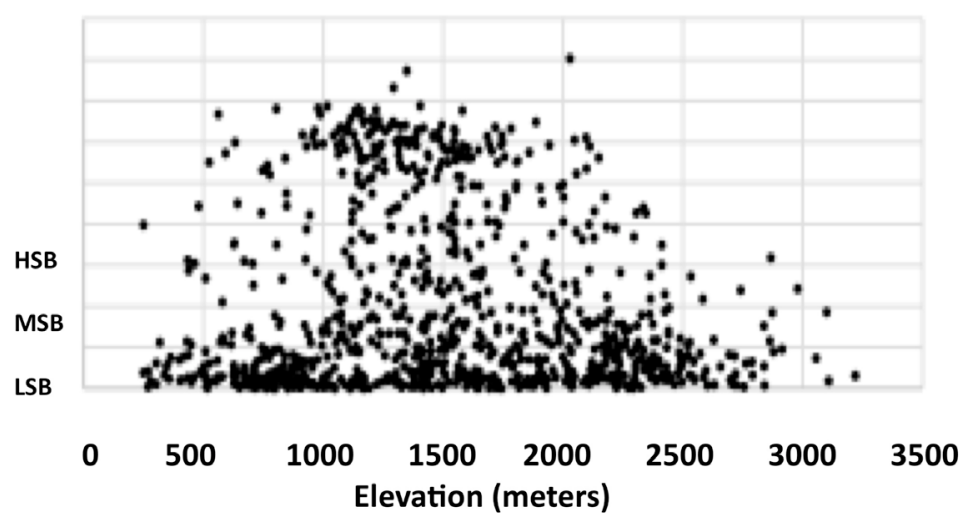

Figure 3. Plot of the sampled $(n=2000)$ frequency distributions of the Rim Fire RdNBR values by elevation.

Table 2. Summary of pre-fire NDVI values by RdNBR classes for the Rim Fire.

\begin{tabular}{cccc}
\hline RdNBR Severity Classes & Max & Mean & Standard Deviation \\
\hline Non-burned & 809 & 503 & 170 \\
Low & 850 & 513 & 199 \\
Moderate & 868 & 555 & 159 \\
High & 844 & 592 & 125 \\
\hline
\end{tabular}

all Rim Fire burned areas were categorized, the HBS areas showed the lowest mean elevation, followed by MBS and LBS classes, with a 250 meter average difference between the LBS and HBS categories (Table 3).

\subsection{Slope and Aspect}

The majority of HBS areas were located between slopes of 5 percent and 30 percent, with few HBS areas detected at slopes steeper than 40 percent (Figure 4). Comparisons of the frequency distributions of slope values showed a significant difference (K-S $p<0.05$ ) between the sampled LBS and HBS classes. Likewise, many HBS areas were located on south-facing aspects, with fewer HBS areas detected on north- and east-facing areas (Figure 4).

\subsection{Fire History}

When all Rim Fire burned areas were categorized, the HBS areas showed the highest average years since fire 

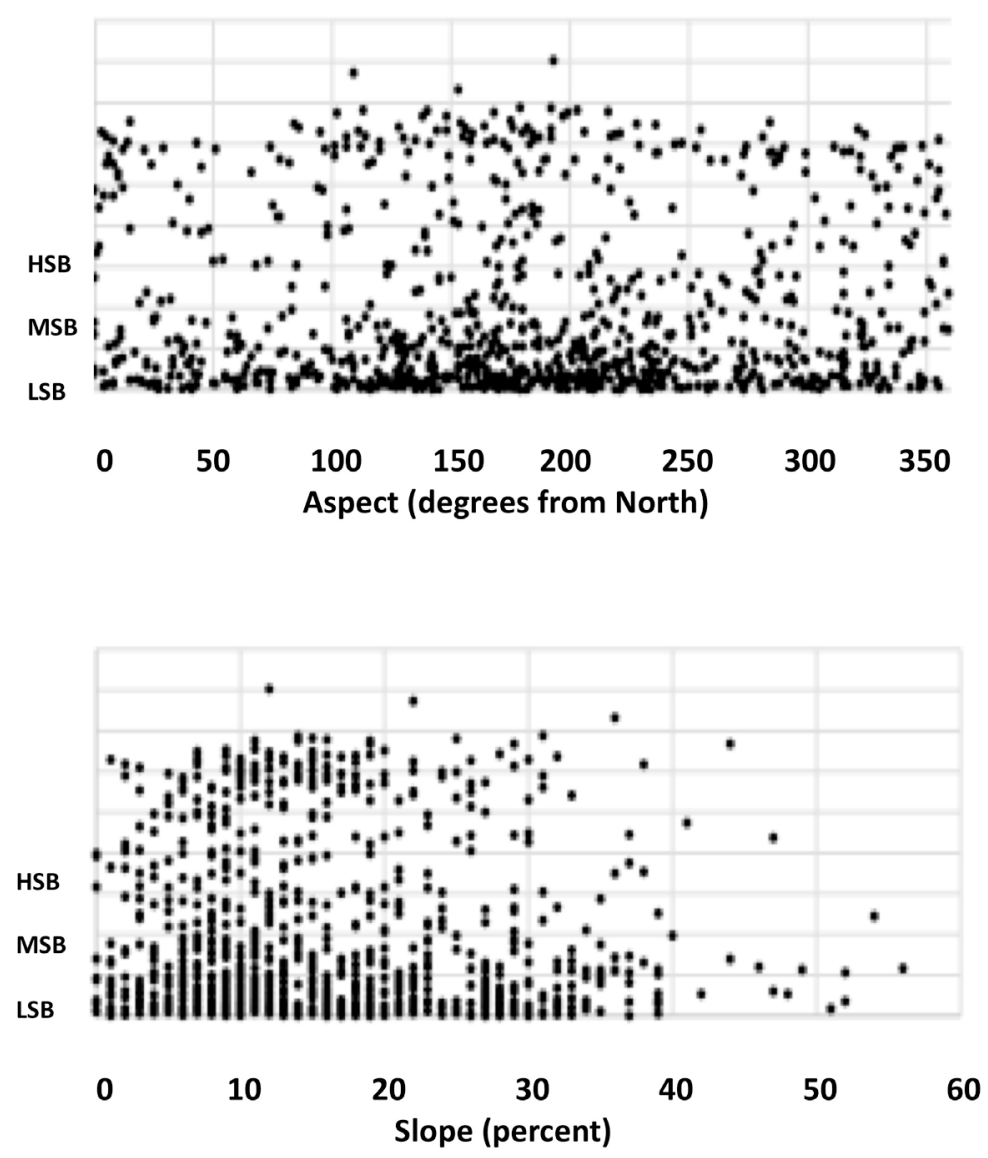

Figure 4. Plots of the sampled $(n=2000)$ frequency distributions of the Rim Fire RdNBR values by slope and aspect.

Table 3. Summary of elevation (m) values by RdNBR classes for the Rim Fire.

\begin{tabular}{cccc}
\hline $\begin{array}{c}\text { RdNBR } \\
\text { Severity Classes }\end{array}$ & Max & Mean & Standard Deviation \\
\hline Non-burned & 3041 & 1582 & 621 \\
Low & 3025 & 1617 & 564 \\
Moderate & 3022 & 1507 & 501 \\
High & 3009 & 1366 & 372 \\
\hline
\end{tabular}

(YSF) at $50 \mathrm{yr}$, followed by MBS and LBS classes, both with average YSF estimated at 40 yr (Table 4). Comparisons of the frequency distributions of YSF values showed a significant difference (K-S $p<0.001)$ between the LBS and HBS classes (Figure 5). The LBS class covered a higher fraction of areas where the YSF was less than $25 \mathrm{yr}$, compared to the HBS class, which covered a higher fraction of areas where the YSF was greater than $60 \mathrm{yr}$.

The majority of the Rim Fire burned areas within YNP had experienced wildfires within the past 20 years, particularly from the Ackerson Fire of 1996 (Figure 6). Despite the short period of 17 years between the Ackerson Fire and the Rim Fire, all Rim Fire burn severity classes were well-represented within the Ackerson Fire boundary, regardless of the RdNBR burn severity class determined for the Ackerson Fire. Nevertheless, Potter [18] estimated using the RdNBR methodology that only about $20 \%$ of the 23,944 ha Ackerson fire area was within the HBS class, and most of that HBS area was located outside of YNP to the west.

Only the southern section of the Rim Fire within YNP, located roughly between Long Gulch and Crane Flat, 

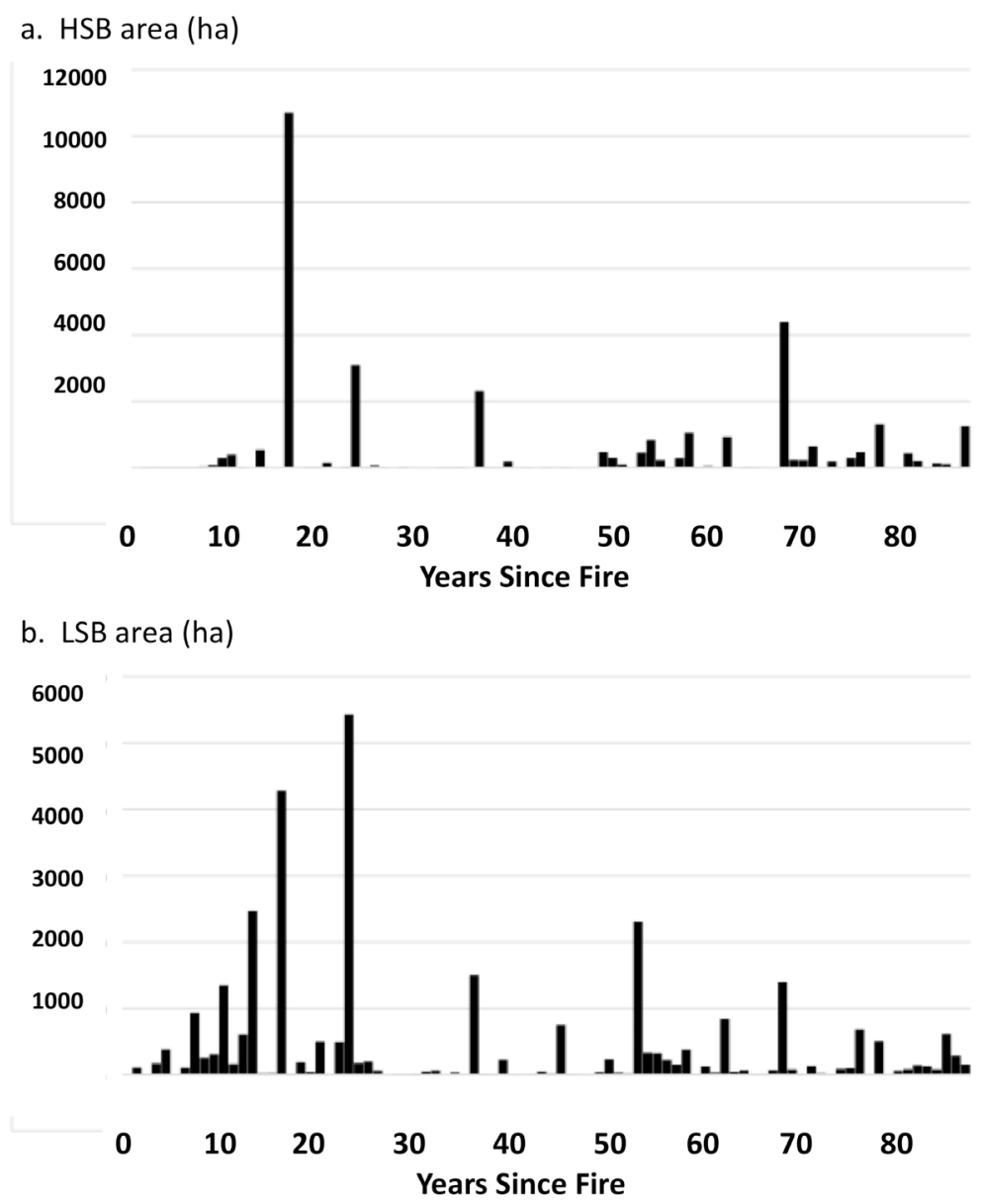

Figure 5. Plots of the frequency distributions of all Rim Fire HBS and LBS class areas by years since last fire.

\section{Table 4. Summary of years since fire by RdNBR classes for the Rim Fire.}

\begin{tabular}{cccc}
\hline RdNBR & Median & Mean & Standard Deviation \\
Severity Classes & 26 & 47 & 34 \\
Non-burned & 26 & 40 & 30 \\
Low & 26 & 41 & 31 \\
Moderate & 40 & 50 & 33 \\
High & &
\end{tabular}

had not experienced many wildfires within the past 135 years ([1] and FRAP). Despite the long period (>100 years) between the past fires and the Rim Fire, all Rim Fire burn severity classes were well-represented within this southern section burned in 2013. A notable portion of Aspen Valley that had not burned in over 100 years was also unburned by the Rim Fire.

In the Rim Fire burned areas outside of YNP, the two largest previously burned areas were the Granite Fire of 1973, the Stanislaus Complex fires of 1987 (at the western extreme of the Rim Fire area), and the Rogge Fire of 1996 (Figure 5). Despite the variable period (17 - 40 years) between these past fires and the Rim Fire, all Rim Fire burn severity classes were well-represented within these three past burned areas. The most extensive HBS area outside of YNP from the Rim Fire that had not burned within the past 135 years was located roughly between Niagara Creek and Meyers Ranch. 


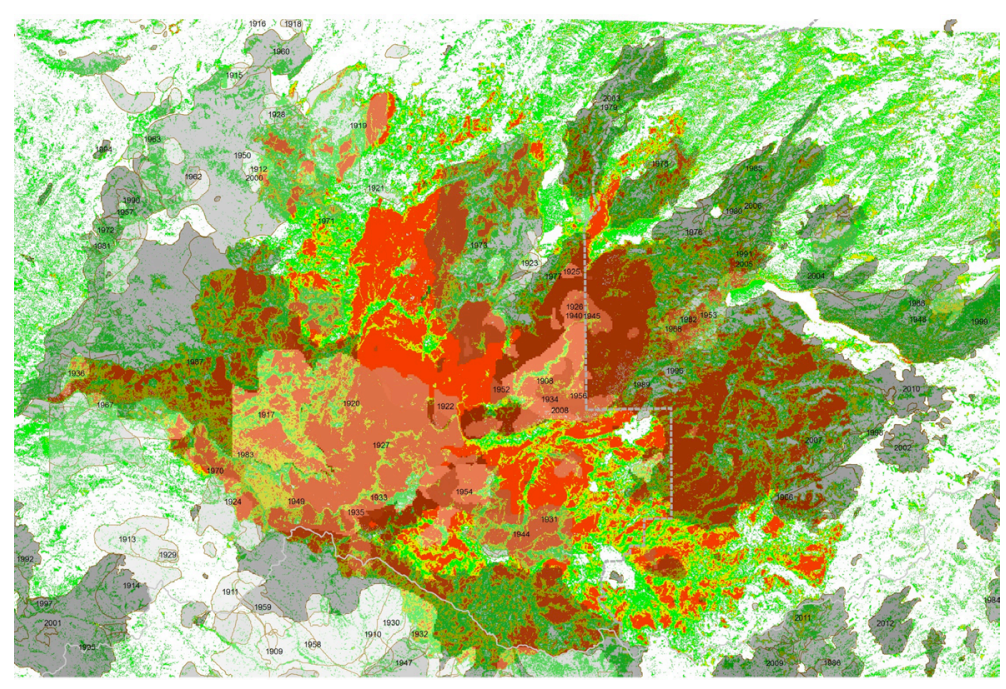

Burn Severity Classes

High

Moderate

Low

Non-burned

Figure 6. Burn severity classes for the 2013 Rim Fire area, shaded by the years since last wildfire (FRAP, 2013). Darkest shaded areas had burned within the past 20 years. Past fire years are labeled. The Yosemite National Park boundary (dashed) is shown in lighter lines.

\section{Discussion}

The results from this geographic analysis of burn severity classes for the 2013 California Rim Fire enabled the cross tabulation of areas of interest where several key ecological and topographic variables co-occurred. For instance, 23,669 ha (or 44\%) of the total HBS area from the Rim Fire were classified as conifer forest cover located at elevations below $2000 \mathrm{~m}$, and nearly 2,865 ha of the total MBS and HBS areas combined were classified as vegetation cover where the duration since the last fire was greater than $25 \mathrm{yr}$.

Previous field studies have implied that the percentage of high-severity fires in conifer forests of California has been higher in areas dominated by smaller-diameter trees than in areas with larger diameter trees [4] [19]. However, Landsat imagery at a 30-meter resolution cannot readily discriminate tree diameter classes to support this type of analysis for the Rim Fire burned areas.

In 2014 and beyond, Landsat images can be used to monitor vegetation recovery from the Rim Fire and to document forest regrowth trajectories in all categories of burn severity [18] [20] [21]. These previous studies have shown that NDVI typically increases rapidly over the first five years following a stand-replacing fire, doubling in value by about 10 years after the burn, and then leveling off to approach pre-fire (mature) forest stand values by about 25 - 30 years after the fire event. A complementary approach would be to combine CALVEG categories with the US Department of Agriculture's National Agricultural Imagery Program (NAIP) 1-meter resolution aerial imagery of pre-fire and post-fire NDVI. NAIP is similar in quality and scale to traditional aerial photographs, but with the advantages of enhanced spectral information and digital format [22]. This 
approach could produce downscaled CALVEG products for the Rim Fire area suitable for comparison to small plot $\left(<25 \mathrm{~m}^{2}\right)$ pre- and post-fire vegetation surveys.

\section{Conclusion}

The 2013 Rim Fire in the Sierra Nevada of California affected over 158,500 ha, 33\% of which was detected as high burn severity by Landsat image analysis. The most typical ecosystem habitat detected within high severity burns areas was Ponderosa pine-Mixed Conifer forest, located between the elevations of 1000 and 2000 meters or on slopes between 5 and 30 percent. The low burn severity areas covered a higher fraction of areas where the duration since last fire was less than 25 years, compared to high burn severity, which covered a larger fraction of areas where the duration since last fire was greater than 60 years.

\section{Acknowledgements}

The author thanks National Park Service scientists Douglas (Gus) Smith, Matthew Brooks, and Kent Van Wagtendonk for comments on an earlier version of this paper.

\section{References}

[1] CAL FIRE (2013) Rim Fire Incident Information. California Department of Forestry. http://cdfdata.fire.ca.gov/incidents/incidents_details_info?incident_id=905

[2] National Park Service (NPS) (2013) Yosemite National Park Rim Fire 2013 Burned Area Emergency Response Plan. Yosemite National Park, $99 \mathrm{p}$.

[3] Batker, D., Christin, Z., Schmidt, R. and de la Torre, I. (2013) Preliminary Assessment: The Economic Impact of the 2013 Rim Fire on Natural Lands. Report Version 1.2, Earth Economics, Tacoma, 53 p.

[4] Miller, J.D., Knapp, E.E., Key, C.H., Skinner, C.N., Isbell, C.J., Creasy, R.M. and Sherlock, J.W. (2009) Calibration and Validation of the Relative Differenced Normalized Burn Ratio (RdNBR) to Three Measures of fire Severity in the Sierra Nevada and Klamath Mountains, California, USA. Remote Sensing of Environment, 113, 645-656. http://dx.doi.org/10.1016/j.rse.2008.11.009

[5] Kokaly, R.F., Rockwell, B.W., Hiare, S.L. and King, T.V.V. (2007) Characterization of Post-Fire Surface Cover, Soils, and Burn Severity at the Cerro Grande Fire, New Mexico, Using Hyperspectral and Multispectral Remote Sensing. Remote Sensing of Environment, 106, 305-325. http://dx.doi.org/10.1016/j.rse.2006.08.006

[6] Hunt, E.R and Rock, B.N. (1989) Detection of Changes in Leaf water Content Using near and Middle-Infrared Reflectances. Remote Sensing of Environment 30, 43-54. http://dx.doi.org/10.1016/0034-4257(89)90046-1

[7] Gao, B.C. (1996) NDWI-A Normalized Difference Water Index for Remote Sensing of Vegetation Liquid Water from Space. Remote Sensing of Environment, 58, 257-266. http://dx.doi.org/10.1016/S0034-4257(96)00067-3

[8] Chuvieco, E., Riano D., Aguado, I. and Cocero D. (2002) Estimation of Fuel Moisture Content from Multitemporal Analysis of Landsat Thematic Mapper Reflectance Data: Application in Fire Danger Assessment. International Journal of Remote Sensing, 23, 2145-2162. http://dx.doi.org/10.1080/01431160110069818

[9] Dennison, P.E., Roberts, D.A., Peterson, S.H. and Rechel, J. (2005) Use of Normalized Difference Water Index for Monitoring Live Fuel Moisture. International Journal of Remote Sensing, 26, 1035-1042.

http://dx.doi.org/10.1080/0143116042000273998

[10] van Wagtendonk, J.W. and Root, R.R. (2003) The Use of Multi-Temporal Landsat Normalized Difference Vegetation Index (NDVI) Data for Mapping Fuel Models in Yosemite National Park, USA. International Journal of Remote Sensing, 24, 1639-1651. http://dx.doi.org/10.1080/01431160210144679

[11] Miller, J.D. and Yool, S.R. (2002) Mapping Forest Post-Fire Canopy Consumption in Several Overstory Types Using Multi-Temporal Landsat TM and ETM Data. Remote Sensing of Environment, 82, 481-496. http://dx.doi.org/10.1016/S0034-4257(02)00071-8

[12] Chander, G., Markham, B. and Helder, D. (2009) Summary of Current Radiometric Calibration Coefficients for Landsat MSS, TM, ETM+, and EO-1 ALI Sensors. Remote Sensing of the Environment, 113, 893-903. http://dx.doi.org/10.1016/j.rse.2009.01.007

[13] Avery, T.E. and Berlin, G.L. (1992) Fundamentals of Remote Sensing and Airphoto Interpretation. Prentice Hall, Upper Saddle River, $472 \mathrm{p}$.

[14] Key, C.H. and Benson, N.C. (2004) Landscape Assessment: Ground Measure of Severity, the Composite Burn Index; and Remote Sensing of Severity, the Normalized Burn Ratio. In: Lutes, D.C., Keane, R.E., Caratti, J.F., Key, C.H., 
Benson, N.C. and Gangi, L.J., Eds., Firemon: Fire Effects Monitoring and Inventory System, USDA Forest Service General Technical Report RMRS-GTR-XXX.

[15] Lentile, L., Holden, A., Smith, A., Falkowski, M., Hudak, A., Morgan, P., et al. (2006) Remote Sensing Techniques to Assess Active Fire Characteristics and Post-Fire Effects. International Journal of Wildland Fire, 15, 319-345. http://dx.doi.org/10.1071/WF05097

[16] Lehmann, E. (2006) Nonparametrics: Statistical Methods Based on Ranks, Springer, New York, 464 p.

[17] Cleland, D.T., Freeouf, J.A., Keys, Jr., J.E., Nowacki, G.J., Carpenter, C and McNab, W.H. (2007) Ecological Subregions: Sections and Subsections of the Conterminous United States [1:3,500,000], Sloan, A.M., Cartog. Gen. Tech. Report WO-76. Department of Agriculture, Forest Service, Washington DC.

[18] Potter, C. (2014) Ten Years of Forest Cover Change in the Sierra Nevada Detected Using Landsat Satellite Image Analysis. International Journal of Remote Sensing, (under Review).

[19] Bond, M.L., Lee, D.E., Bradley, C.M. and Hanson, C.T. (2009) Influence of Pre-Fire Tree Mortality on Fire Severity in Conifer Forests of the San Bernardino Mountains, California. The Open Forest Science Journal, 2, 41-47. http://dx.doi.org/10.2174/1874398600902010041

[20] Viedma, O., Melia, J., Garcfa-Hara, J. and Segarro, D. (1996) Monitoring Forest Regrowth Rates after Fire with Multitemporal Landsat-TM Imagery. EARSEL Advances in Remote Sensing. Remote Sensing and GIS Applications to Forest Fire Management, 4, 145-154.

[21] van Leeuwen, W.J.D. (2008) Monitoring the Effects of Forest Restoration Treatments on Post-Fire Vegetation Recovery with MODIS Multi-Temporal Data. Sensors, 8, 2017-2042. http://dx.doi.org/10.3390/s8032017

[22] Davies, K.W., Peterson, S.L., Johnson, D.D., Davis, D.B., Madsen, M.D., Zvirzdin, D.L. and Bates, J.D. (2010) Estimating Juniper Cover from National Agriculture Imagery Program (NAIP) Imagery and Evaluating Relationships between Potential Cover and Environmental Variables. Rangeland Ecology and Management, 63, 631-634. http://dx.doi.org/10.2111/REM-D-09-00129.1 
Scientific Research Publishing (SCIRP) is one of the largest Open Access journal publishers. It is currently publishing more than 200 open access, online, peer-reviewed journals covering a wide range of academic disciplines. SCIRP serves the worldwide academic communities and contributes to the progress and application of science with its publication.

Other selected journals from SCIRP are listed as below. Submit your manuscript to us via either submit@scirp.org or Online Submission Portal.
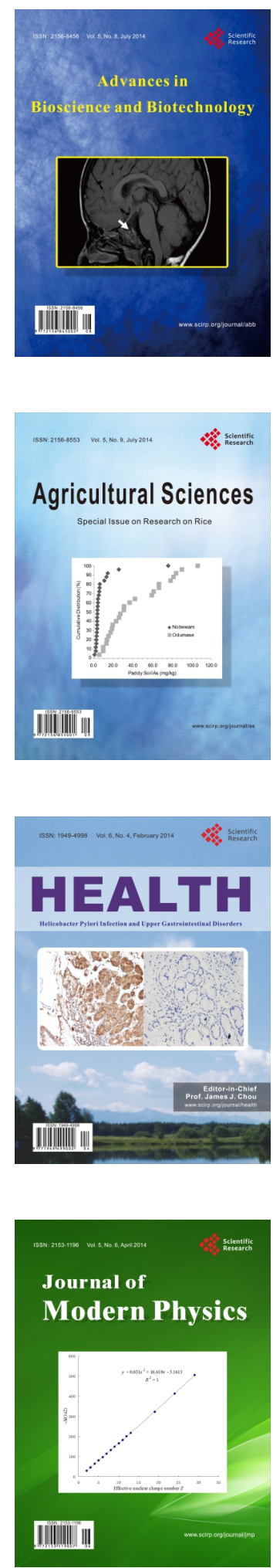
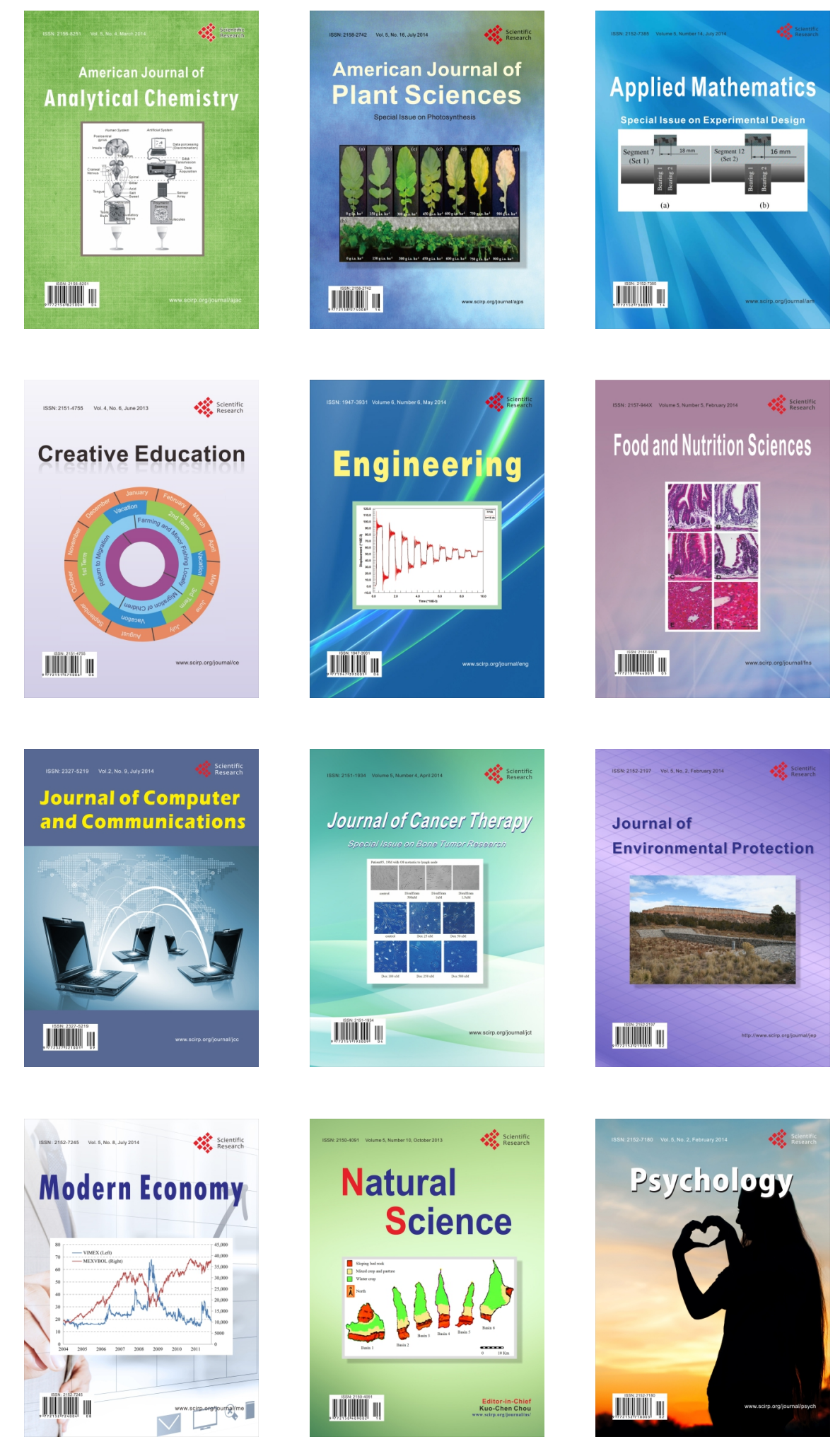